\title{
Impacts of Direct Metacognitive Instructions on Self-Actualization
}

\author{
Fariba Dezhbankhan ${ }^{1}$, Diana Lea Baranovich ${ }^{1} \&$ Nabeel Abedalaziz ${ }^{1}$ \\ ${ }^{1}$ Department of Educational Psychology and Counselling, Faculty of Education, University of Malaya, Malaysia \\ Correspondence: Fariba Dezhbankhan, Department of Educational Psychology and Counselling, Faculty of \\ Education, University of Malaya, Malaysia. E-mail: fdezhban@gmail.com
}

Received: April 29, 2020

doi:10.5539/ies.v13n11p1
Accepted: July 2, $2020 \quad$ Online Published: October 9, 2020

URL: https://doi.org/10.5539/ies.v13n11p1

\begin{abstract}
Education has a crucial role in improving opportunities for lifelong learning and helping students to move towards their self-actualizing goals. Applying metacognitive interventions facilitate conceptualization and operationalization of such holistic approach of education. This study investigated the impacts of twelve hours metacognitive intervention, 'Direct Metacognitive Instructions' (DMI) on self-actualization process among 31 students using quasi-experimental (pre-test-post-test) design. The large effect size (Partial $\eta^{2}=.818,95 \%$ confidence intervals) implied that DMI has a statistically significant impact in fostering student's self-actualization. This study has implications for designing and implementing multidimensional metacognitive interventions targeting self-actualization and evaluating cognitive, behavioral and affective effects of such interventions.
\end{abstract}

Keywords: metacognition, Direct Metacognitive Instructions (DMI), self-actualization

\section{Introduction}

Presumably acquisition of enduring knowledge that assist students in all areas of their life and building up the highest level of personal growth that is self-actualization is among the most objectives of educational system in every country despite of the cultural differences (Amir Kiaei, 2014, Burleson, 2005). In fact, during the decades educational policies has shifted to include considerations such as self-realization (Broudy, 1954; Cangemi, 1987), self-actualization (Goldstein, 1959), individuals' endeavours directed at achieving goals (Hanlon, 1968), and flourishing (Cigman, 2014). Hanlon (1968) stated that self-actualization is the principal function of education and education is 'the process of the individual human being making of himself what he wishes to be' (p. 133). Investment in strategies that targeting student's personal development besides academic achievements pave the way for conceptualization and operationalizion of such holistic approach of education. Among these strategies are targeted interventions for encouraging lifelong learning, which help scaffold the never-ending self-growth. Lifelong learning, itself, requires mechanisms to be implemented. One of these mechanisms is metacognition (Worrall \& Bell, 2007; Marra et al., 2017). In fact, metacognition is a predominant feature of lifelong learning (Wang et al., 2014; Nielsen et al., 2009; Blank, 2000).

\subsection{Theoretical Framework}

Metacognition was simply defined as 'thinking about thinking' (Flavell, 1979, p. 906), but since Flavell's first attempt to define 'metacognition' a variety of accounts of the term appeared in the literature (Papaleontiou-Louca, 2014). To describe the nature and components of metacognition and their interactions three groups of theoretical models including classic, descriptive, and procedural models are transpired. By providing essential concepts, classic models try to describe the nature of metacognition. Descriptive models underline components, functionalities, and facets of metacognition and their relationships. Procedural models highlight a series of sequential stages or processes of metacognition (Peña-Ayala \& Cárdenas, 2015).

To date knowledge, regulation and experience are known as main components of metacognition; However, processes of planning, goal setting, monitoring, evaluation, reflection, and awareness have been recognized as other components and functionalities of metacognition. Individuals' personal responsibility for performance of their mental activities is also known as the reflective property of metacognition components (Peña-Ayala \& Cárdenas, 2015). Lai (2011) acknowledged that due to complexity of metacognition, most of researchers have preferred to apply one or few aspects of the construct. Accordingly, interventions and measures designed to focus somewhat on only a single dimension, facet or component of metacognition. We, by combining the well-known 
phenomena involved in the above mentioned models of metacognition and Hanlon's conceptual and climate sub-systems, created a multidimensional intervention and called it "Direct Metacognitive Instructions".

Self-actualization which is regarded as a motive, active striving, or goal entailing behaviors aimed at the fulfilment of personal potentials was introduced by Kurt Goldstein in 1939 (Waterman, 2014). Later, Maslow (1943) introduced self-actualization as the peak of the hierarchy of needs that may be manifested when all the other lower needs are satisfied. According to Maslow, self-actualization refers to the one's desire to fully actualize his potentiality. Roger $(1959,1962)$ also calls a self-actualized person as a fully functioning person.

Self-actualization processes are explained with metacognition theories and models too. For example Hanlon (1968) defined three functionally differentiated subsystems requirements for self-actualization comprising (i) conceptual subsystem elements including an individual's unique worldview, a true vision of the self, and a set of specified self-actualizing goals that pave the way for willing, planning, monitoring, and evaluation;(ii) climate subsystem elements including an optimum freedom and self-control element that enable persons to manage their actions to perform the tasks at hand, an energizing element which provides internal force required to accomplish the task, and a linkage element which provides social support for individuals that create an environment needed for self-actualization; and (iii) environmental subsystem elements including aspects needed for implementing self-actualization plans, and supportive aspects needed for accomplishing self-actualization tasks. The conceptual subsystem elements are manifested in metacognitive self-knowledge and setting goals and planning processes of metacognition, respectively. The climate subsystem elements are pursued in metacognition functions (such as individuals' motivation and commitment to achieve their goals), and monitoring and evaluation processes, accordingly.

\subsection{Relevant Literature Review}

While there is a substantial body of research binding metacognition to different aspects of psychosocial performance, there is a limited research investigating the role of metacognition in predicting or indicating self-actualization (Amir Kiaei, 2014). For example, metacognition has shown to positively related to self-actualization as the goal of education and the overall goal of human being, that is, well-being (Amir Kiaei, 2014). In her study, she found out that metacognitive abilities play an important role in paving the way towards self-actualization. She described that to develop and satisfy cognitive needs, one is required to be equipped with the knowledge of cognition and regulation to manage his or her thinking. Thus, improvement in metacognitive abilities and skills or application of appropriate metacognitive strategies enables individuals to overcome the challenges raised by cognitive activities, which are seen as jumping step to self-actualization. She concluded that if self-actualization is set as the main goal of human being, one is required to go through all metacognitive stages in order to realize it. In the pathways toward self-actualization, one should try to plan, monitor, evaluate, and regulate his image and real self so that he can identify and fulfill his real potentials. Sperling et al. (2004) also found that learning metacognitive skills improve sense of self-efficacy, which is positively related to self-actualization of students.

\subsection{Research Objective}

Development of metacognitive competencies in childhood and adolescence has been the subject of many studies. On the other hand, the effectiveness of metacognitive interventions in either educational settings or quality of life has been acknowledged by researches. However, inadequate scholarly efforts have been made to investigate the effects of metacognitive interventions targeting student's personal development. We conduct this study to highlight the role of metacognitive interventions in fostering students' self-actualization as a goal of education; hence, the aim of the present study was to evaluate the effects of a metacognitive intervention, "Direct Metacognitive Instructions (DMI)" on self-actualization among university students in Tehran.

\section{Method}

\subsection{Research Design}

The design of this research was quasi-experimental (pre-test-post-test).

\subsection{Operational Definition}

In this study, self-actualization refers to actualizing best potentials of an individual (Rogers, 1951; Maslow, 1968) and consists of: (i) desire to actualize potentiality (Jones \& Crandall, 1986); (ii) actualizing initiation which includes the ability of an individual to determine or generate situations and circumstances that might lead to personal growth as well as his/her ability to plan steps to reach specific personal growth goals; and using available resources and self-motivation to accomplish self-change related goals (Robitschek et al., 2012); and (iii) actualizing disposition which includes experiencing openness to experience and establishing self-reference in 
terms of consistency and spontaneous (Leclerc et al., 2003).

\subsection{Research Question and Hypothesis}

Based on the purpose of the study, "to determine the extent to which DMI influence self-actualization", we wanted to know, "Does DMI foster students' self-actualization?" Hence, we plan to test this hypothesis: DMI fosters students' self-actualization. Taking the hierarchy-of-hypotheses approach (Heger et al., 2013), we formulated sub-hypotheses based on the dimensions and factors included in instruments. Figure 1 illustrates the graphical representation of research hypotheses.

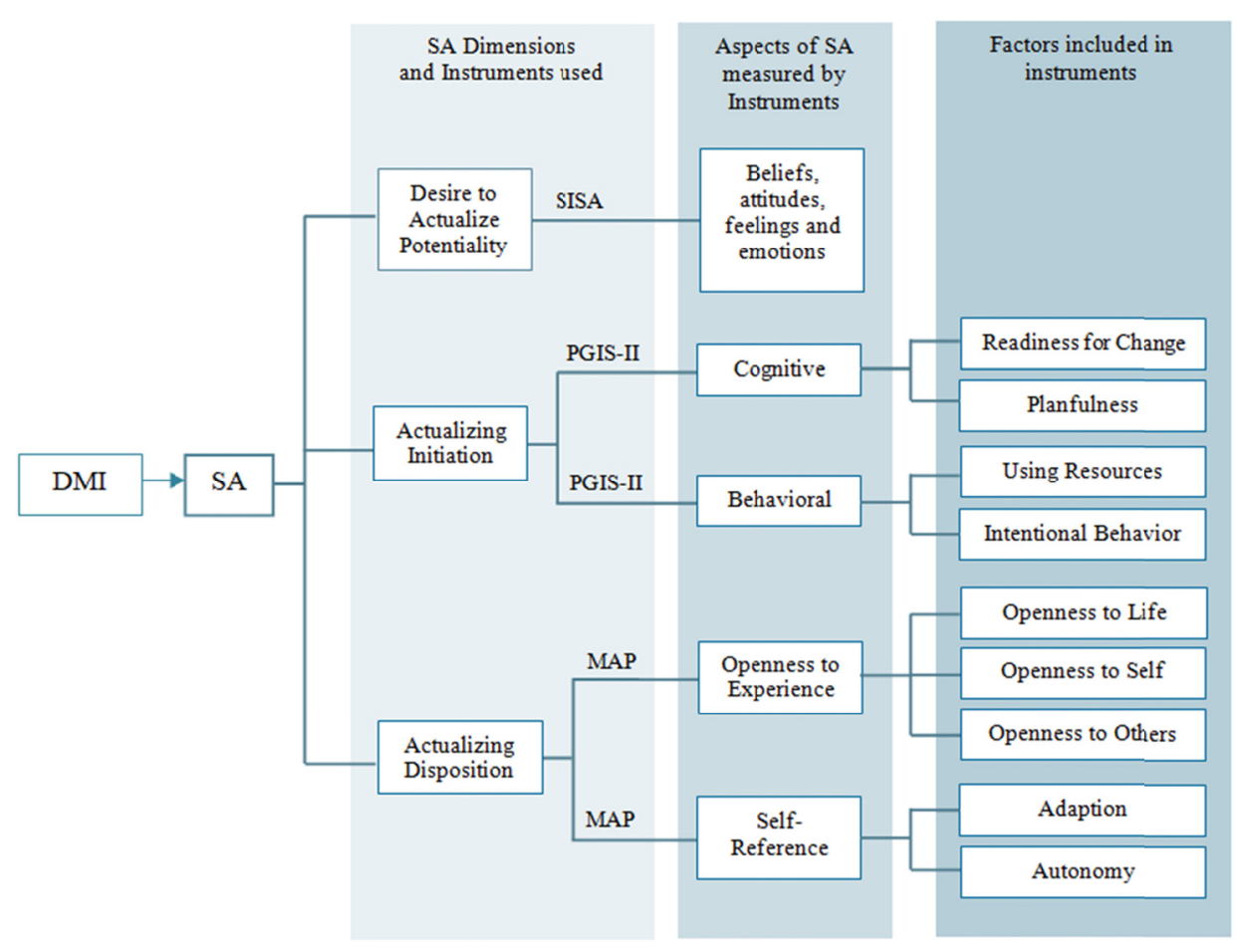

Figure 1. Graphical representation of research hypotheses

\subsection{Population and Sampling Procedure}

The target population for this study was university students. The sample was selected amongst the newly enrolled postgraduate students (Masters) of four departments of a public university in Tehran. The University admitted 36 students to these four departments in 2018-2019. After discussing the issue with the Heads of the Departments and the Dean for Educational Affairs (who were participated in the need assessment phase of the DMI design), necessary explanations were given to the students and they were requested to voluntarily attend the training course if they liked. Overall, 32 students participated in this study. One of the participants in the experimental group left the group. Thus, at the end of the research, we collected data from 31 students. Experimental group consisted of 16 subjects ( 7 female, 9 male) and control group consisted of 15 subjects ( 7 female, 8 male). The mean age for the sample, in both the experimental and the control group was between 26 and 30 years.

\subsection{Materials and Instruments}

\section{5.1 Direct Metacognitive Instructions (DMI)}

To design DMI, we used the ADDIE method that applies iterative process to design instructional interventions (Branch, 2009). Two experts through witnessing design process, making notes, suggesting changes, revising the course, approving and making judgment helped us to validate the DMI. DMI consists of seven modules and each module deals with nature, component, function or processes of metacognition. First module, 'An Introduction to the metacognition, helped students build an underlying basis to understand what metacognition is and how it contributes to learning. Students realized their own learning style and preferences in learning situations in second module, 'Self-knowledge'. In third module, 'Commitment and Motivation', students understood the role of 
personal commitment and motivation in their success in learning and various factors that may affect motivation.

Modules four to seven comprised processes of metacognition and arranged to follow the Plan-Do-Check-Act (PDCA) principles to demonstrate the continuous improvement of metacognition. In fourth module, 'Goal Setting and Planning', students practiced how to set Specific, Measurable, Achievable, Result-focused, and Time bound (SMART) goals and plan to achieve their goals. The aim of teaching individuals to set their goals and develop a plan to work toward achieving those goals was giving help to them to begin to be self-directed learners on the one hand and equip them with versatile skills for success in their life on the other hand (Wilson \& Conyers, 2016). In fifth module, 'Resource Management and Implementation', students familiarized with their limited cognitive and other resources they have for a given task and learned how to use available resources. They learned that this stage refers to the organizing and implementing the plan and may be a hard part since they have to put words into actions (Abuhav, 2017). In sixth module, 'Monitoring and Evaluation', students acquired self-management skills regarding monitoring and evaluating goal-based progress and the scope of monitoring and evaluation activities. In the last module, 'Continuous Improvement', students gained knowledge to adjust their plan or execute activities in a different manner.

\subsubsection{Instruments}

Based on the operational definition of self-actualization we used the Persian version of (i) The Short Index of Self Actualization Inventory (SISA; Jones \& Crandall, 1986); (ii) Personal Growth Initiative Scale-II (PGIS-II; Robitschek et al., 2012); and (iii) The Measure of Actualization of Potentials (MAP; Leclerc et al., 2003). The total score of self-actualization was calculated by summation of the standardized scores obtained from each measure. Hosseini Dolatabadi et al. (2014) examined the psychometric properties of the Persian version of SISA. They evaluated the construct validity of the scale through convergent validity with the application of Shostrom's (1964) Personality Orientation Inventory (POI) and described that there is a statistically significant correlation (.67) between Persian version of SISA and POI, which supports high validity of the scale. The Cronbach's alpha was reported .67 in their study. Joshanloo and Ghaedi (2009) investigated the psychometric properties of the Persian version of PGIS-II in university students. Based on their study, internal consistency of the scale was 0.87 indicating that it has suitable internal consistency. Taj et al. (2013) reported reliability and validity estimates for the Persian version of the MAP. The Cronbach's alpha value was found .83 for the full scale in their study.

\subsection{Procedure}

Prior to recruiting participants in groups, we obtained University approval. We also followed the University Research Protocol and ethical standards regarding privacy, confidentiality, anonymity, informed consent and data preservation. We conduct a pre-test to experimental and control groups using self-ratings of a battery of questionnaires. Between $25^{\text {th }}$ of September and the $20^{\text {th }}$ of November of 2018, we gave DMI in eight (90 min.) sessions to the experimental group only. Finally, we conducted a post-test to both groups. Participants were invited to a dinner at the end of the experiment.

\section{Results}

To test the effect of DMI on self-actualization and its dimensions, we conducted one way analyses of covariance (ANCOVA). Preliminary of data analysis, exploratory data analysis (EDA) has been conducted to check the assumptions of normality (using Kolmogorov-Smirnov $z$ value $(K S \mathrm{z})(p>.05)$ ), dispersion (using skewness and Kurtosis values (e.g., within \pm 2 standard deviations)), homogeneity of regression slopes (using the $F$ test), and homogeneity of variance (using Levene's test) for all hypotheses. EDA results revealed that all assumptions are met. Assumption of linearity was analyzed creating a scatterplot for both experimental and control groups. Figure 2 demonstrates that a linear relationship exists between the dependent variable and covariate. 


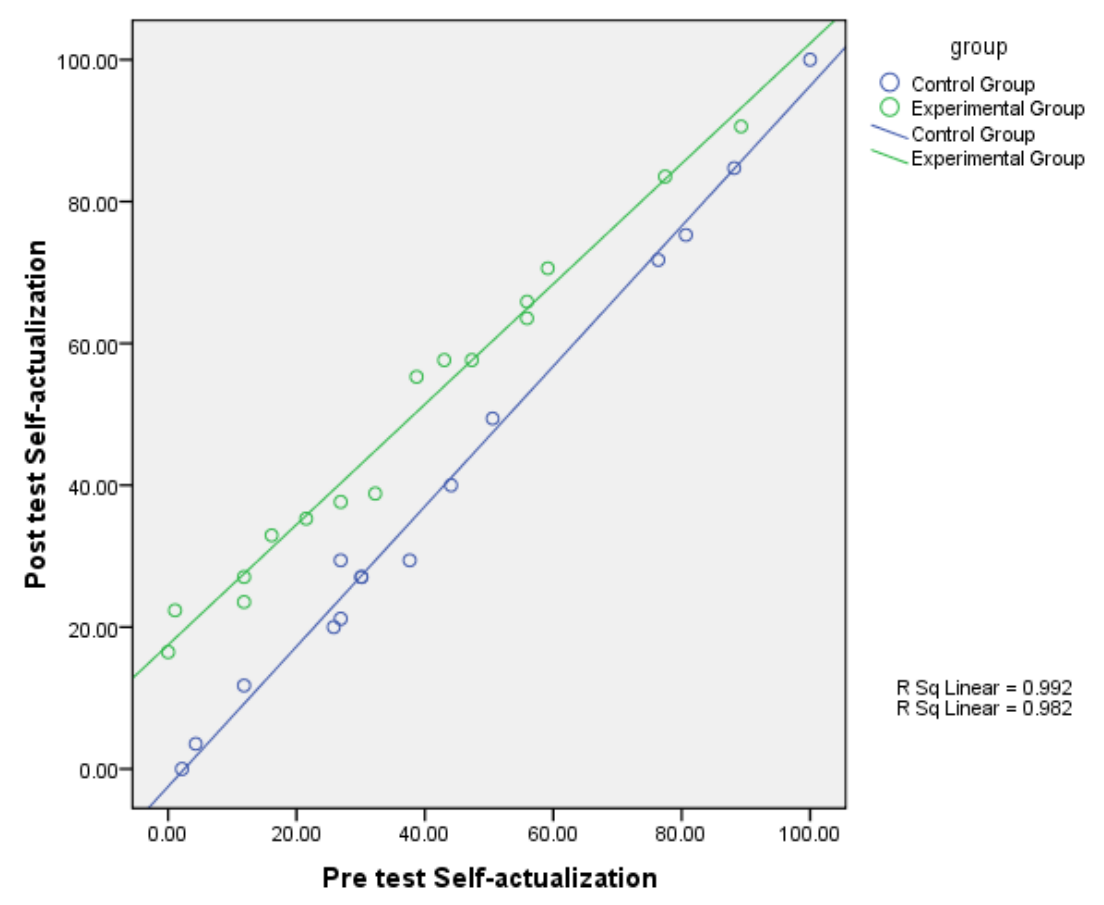

Figure 2. Scatterplot of pre-test, post-test among experimental and control groups

After adjustment by covariates (pre-tests scores), as displayed in table 1, a statistically significant effect for self-actualization was found $[F(1,28)=126.198, p=.000,(p<.05)]$. The strength of the relationship between DMI and self-actualization was significant, with partial $\eta^{2}=.818,95 \%$ confidence intervals. It means that $81.8 \%$ of variance in self-actualization could be attributed to DMI which is a large effect size (Mertler \& Reinhart, 2017). The adjusted marginal means, as demonstrated in table 1 , also shows the difference between experimental and control group after controlling the effect of pre-test. The results also indicated significant main effect for dimensions of desire to actualize potentiality $\left[F(1,28)=19.023, p=.000,(p<.05)\right.$, partial $\left.\eta^{2}=.405\right]$, actualizing initiation $\left[F(1,28)=24.206, p=.000,(p<.05)\right.$, partial $\left.\eta^{2}=.464\right]$ and actualizing disposition $[F(1$, 28) $=169.082, p=.000,(p<.05)$, partial $\left.\eta^{2}=.858\right]$.

Results revealed a significant main effect of cognitive aspects of actualizing initiation $[F(1,28)=9.643, p=.004$, $(p<.05)$, partial $\left.\eta^{2}=.256\right]$ after adjustment for covariate. Among underlying factors of this variable, a significant main effect was found for readiness for change $\left[F(1,28)=10.740, p=.003,(p<.05)\right.$, partial $\eta^{2}$ $=.277]$. However, there was no statistically significant effect for planfulness $F(1,28)=.690, P=.413,(p>.05)$. No statistically significant effect neither for behavioral aspects of actualizing initiation $F(1,28)=1.898, p=.179$, $(p>.05)$ nor its factors including using resources $F(1,28)=1.314, P=.261,(p>.05)$ and intentional behaviour $F(1,28)=.693, P=.412,(p>.05)$ was found.

The results of ANCOVA also confirmed a statistically significant effect for both dimensions of actualizing disposition including openness to experience $\left[F(1,28)=83.166, p=.000,(p<.05)\right.$, partial $\left.\eta^{2}=.748\right]$ and self-reference $\left[F(1,28)=44.765, p=.000,(p<.05)\right.$, partial $\left.\eta^{2}=.615\right]$. A statistically significant effect was also found for factors underlying these dimensions including: openness to life $(F(1,28)=11.926, p=.002,(p<.05)$, partial $\left.\eta^{2}=.299\right)$; openness to self $\left(F(1,28)=19.602, p=.000,(p<.05)\right.$, partial $\left.\eta^{2}=.412\right)$; and openness to others $\left(F(1,28)=29.410, p=.000,(p<.05)\right.$, partial $\left.\eta^{2}=.512\right)$ as well as adaption $(F(1,28)=17.327, p=.000$, $(p<.05)$, partial $\left.\eta^{2}=.382\right)$; and autonomy $\left(F(1,28)=20.208, p=.000, p<.05\right.$, partial $\left.\eta^{2}=.419\right)$. 
Table 1. Results of ANCOVA analysis

\begin{tabular}{cccc}
\hline \multirow{2}{*}{ Measure } & & ANCOVA Results & \\
\cline { 2 - 4 } Self-Actualization & $\mathrm{F}(1,28)$ & Sig. & .818 \\
Desire to Actualize Potentiality & 126.198 & .000 & .405 \\
Actualizing initiation & 19.023 & .000 & .464 \\
Cognitive aspect & 24.206 & .000 & .256 \\
Readiness for Change & 9.643 & .004 & .277 \\
Planfulness & 10.740 & .003 & .024 \\
Behavioral aspect & .690 & .413 & .063 \\
Using resources & 1.898 & .179 & .045 \\
Intentional bahavior & 1.314 & .261 & .024 \\
Actualizing disposition & .693 & .412 & .858 \\
Openness to experience & 169.082 & .000 & .748 \\
Openness to life & 83.166 & .000 & .299 \\
Openness to self & 11.926 & .002 & .412 \\
Openness to others & 19.602 & .000 & .512 \\
Self-reference & 29.410 & .000 & .615 \\
Adaption & 44.765 & .000 & .382 \\
Autonomy & 17.327 & .000 & .419 \\
\hline
\end{tabular}

A comparison of the adjusted means as indicated in table 2 revealed the differences in different dimension of self-actualization among students who exposed to DMI and students who not exposed to the independent variable prior and after having control over the pre-test effect.

Table 2. Adjusted and unadjusted means

\begin{tabular}{|c|c|c|c|c|c|c|c|c|}
\hline & \multicolumn{4}{|c|}{ Experimental Group $(\mathrm{N}=16)$} & \multicolumn{4}{|c|}{ Control Group $(\mathrm{N}=15)$} \\
\hline & \multicolumn{2}{|c|}{ Adjusted Means } & \multicolumn{2}{|c|}{ Unadjusted Means } & \multicolumn{2}{|c|}{ Adjusted Means } & \multicolumn{2}{|c|}{ Unadjusted Means } \\
\hline & M & SE & $\mathrm{M}$ & SD & $\mathrm{M}$ & $\mathrm{SE}$ & M & SD \\
\hline Self-Actualization & 50.977 & .755 & 48.676 & 22.580 & 36.515 & .779 & 39.372 & 30.445 \\
\hline Desire to Actualize Potentiality & 39.258 & .112 & 37.75 & 5.615 & 40.480 & .123 & 41.73 & 2.840 \\
\hline Actualizing initiation & 47.410 & .272 & 47.19 & 11.010 & 45.414 & .281 & 45.67 & 11.866 \\
\hline Cognitive aspect & 27.055 & .309 & 26.69 & 6.008 & 25.675 & .319 & 26.07 & 8.022 \\
\hline Readiness for Change & 12.115 & .200 & 12.000 & 2.732 & 11.032 & .207 & 11.200 & 3.569 \\
\hline Planfulness & 14.887 & .218 & 14.687 & 3.477 & 14.605 & .226 & 14.866 & 4.763 \\
\hline Behavioral aspect & 20.341 & .289 & 20.50 & 5.704 & 19.769 & .298 & 19.60 & 4.641 \\
\hline Using resources & 8.399 & .206 & 8.687 & 2.495 & 8.071 & .215 & 7.733 & 2.120 \\
\hline Intentional bahavior & 11.990 & .212 & 11.81 & 4.053 & 11.717 & .219 & 11.87 & 3.159 \\
\hline Actualizing disposition & 97.980 & .531 & 97.44 & 10.545 & 86.340 & .548 & 87.07 & 13.301 \\
\hline Openness to experience & 61.115 & .436 & 61.062 & 6.402 & 54.256 & .450 & 54.333 & 8.599 \\
\hline Openness to life & 18.251 & .345 & 18.38 & 2.604 & 16.513 & .356 & 16.33 & 2.968 \\
\hline Openness to self & 21.023 & .372 & 20.75 & 2.352 & 18.573 & .384 & 19.00 & 3.273 \\
\hline Openness to others & 21.805 & .336 & 21.94 & 2.816 & 19.177 & .348 & 19.00 & 2.878 \\
\hline Self-reference & 36.950 & .511 & 36.375 & 4.558 & 32.121 & .528 & 32.733 & 4.905 \\
\hline Adaption & 22.303 & .504 & 22.19 & 2.713 & 19.297 & .520 & 19.47 & 3.357 \\
\hline Autonomy & 14.496 & .244 & 14.19 & 2.316 & 12.942 & .256 & 13.27 & 1.751 \\
\hline
\end{tabular}

\section{Discussion}

We assumed that DMI would foster self-actualization among students who exposed to DMI. Our findings provide supporting proof for DMI influencing self-actualization process from provoking tendency to actualize potentials, initiating and pursuing actualization to actualizing disposition. The results are consistent with Sperling et al. (2004) who found that learning metacognitive skills improve sense of self-efficacy, which is positively related to self-actualization of students. The results are also congruent with Bar-On $(2001,2006)$ who found that 
self-awareness significantly predicts self-realization. Caldwell and Hayes (2016) also identified that metacognition enables individuals to realize their own inimitable potentials.

Findings implied that DMI has a positive effect on speeding up the journey towards self-actualization, improving awareness of the need for change, and accelerating readiness for change. These findings are consistent with Sinatra (2005) who declared that metacognitive awareness helps individuals realize the need for change, concern what needs to be change and available resources which facilitates awareness of the need for change. However, DMI couldn't help students to be planful.

DMI also could not help students to act on the awareness of the need for change, to use available resources, and to increase their intentional or purposive behaviors to accomplish a goal. These findings are in contradict with Limón (2003) who declared metacognition can helps individuals to plan, monitor, and evaluate their own motivations and skills needed for achieving goal of change, plan and monitor activities needed for implementation of the process of change and evaluate the outcomes of such process.

Findings revealed that students, who exposed to DMI, would practice more openness-to-experience. DMI had also potential to improve reflexive capacity (or self-reference) of students, their adaption level to reality and their sense of autonomy. Such findings are congruent with Wiezbicki-Stevens (2009) studies that used the guided reflection activity to develop metacognitive self-knowledge among students through a qualitative research approach. She concluded that students not only realized different aspect of metacognitive self-knowledge but also experienced personal changes following self- knowledge improvement. These personal changes included openness to experience, openness to change, openness to others' opinion, self-confidence and learning from mistakes. Moreover, Schraw et al. (2006) identified that learning metacognitive strategies motivate students using them strategically and autonomously.

\section{Limitations of the Study}

The study undoubtedly takes in some limitations, some of which are to be presented here. The sample of this study was selected amongst a public university in Tehran as a capital of Iran. Hence, the results cannot be generalized to other students or groups in public or private universities in Tehran or other cities of Iran. Moreover, the efficacy of DMI was limited by the available time to deliver the course. While the course was held in 8 sessions (90 minutes), this was less than optimal to use other modes of teaching including workshops and using multimedia supplemental materials appropriately and sufficiently and allow students to work-out on some of the modules. Likewise, employing self-report instruments may yield the risk of common method biases to the measurement of parameters. Failure to back to back translation of instruments into Persian was another limitation of this study. While Ross (2004) and Baykul (1999) believe that the sample size of 30-500 is sufficient when using ANCOVA as a parametric statistical test, the short sample size seems a significant threat. Finally, failure to random assignment of subjects into experimental and control groups were was another weakness of this study.

\section{Conclusion}

This study furnishes an orientation for educational efforts needed for improving opportunities for lifelong learning and helping students to move towards their self-actualizing goals. Such efforts may include promoting researchers and educators to develop and implement relevant interventions targeting self-actualization of students as well as educational administrators to revitalize the aim of education, which is self-actualization. Our findings reveal that giving theoretical foundations needed for developing metacognitive competencies can be useful in fostering self-actualization. However, further research is required to identify which aspects of self-actualization may affect by metacognitive abilities. How metacognition can mediate, indicate, or predict self-actualization among different age groups of students. Which curriculum of metacognition to be developed and which measures should be employed to this end? To provide practical and empirical supports for findings of this study, we call for further experimental researches on: (i) designing multidimensional metacognitive intervention by integrating classic, descriptive and procedural models of metacognition; (ii) investigating the effects of such interventions on different dimensions of self-actualization using different quantitative and qualitative methods and instruments.

\section{References}

Abuhav, I. (2017). ISO 9001: 2015-A Complete Guide to Quality Management Systems. Taylor \& Francis Group, LLC. https://doi.org/10.1201/9781315369808

Amir Kiaei, Y. (2014). The Relationship between Metacognition, Self-Actualization, and Well-Being among University Students. Retrieved from https://digitalcommons.fiu.edu/etd/1367/

Bar-On, R. (2001). Emotional intelligence and self-actualization. In J. Ciarrochi, J. Forgas, \& J. D. Mayer (Eds.), Emotional intelligence in everyday life: A scientific inquiry. New York, NY: Psychology Press. 
Bar-On, R. (2006). The Bar-On model of emotional-social intelligence (ESI). Psicothema, 18, 13-25.

Baykul, Y. (1999). İstatistik metotlar ve uygulamalar (3. bs). Ankara: Anı Yayıncılık.

Blank, L. M. (2000). A metacognitive learning cycle: A better warranty for student understanding? Science Education, 84(4), 486-506. https://doi.org/10.1002/1098-237X(200007)84:4<486::AID-SCE4>3.0.CO;2-U

Branch, R. M. (2009). Instructional Design: The ADDIE Approach. Springer. https://doi.org/10.1007/978-0-387-09506-6

Broudy, H. S. (1954). Building a philosophy of education. Englewood Cliffs, NJ: Prentice-Hall.

Burleson, W. (2005). Developing Creativity, Motivation, and Self-actualization with Learning Systems. International Journal of Human-Computer Studies, 63, 436-451. https://doi.org/10.1016/j.ijhcs.2005.04.007

Caldwell, C., \& Hayes, L. (2016). Self-efficacy and self-awareness: Moral insights to increased leader effectiveness. Journal of Management Development, 35(9), 1163-1173. https://doi.org/10.1108/JMD-01-2016-0011

Cangemi, J. P. (1987). Education and self-actualization. Journal of Instructional Psychology, 14, 164-175.

Cigman, R. (2014). Happiness. In D. Phillips (Ed.), Encyclopaedia of Educational Theory and philosophy (pp. 361-364). Thousand Oaks, CA: SAGE Publications.

Flavell, J. H. (1979). Metacognition and cognitive monitoring: A new area of cognitive-developmental inquiry. Am. Psychol., 34, 906-911. https://doi.org/10.1037/0003-066X.34.10.906

Goldstein, K. (1959). Health as value. In A. H. Maslow (Ed.), New knowledge in human values (pp. 178-188). Chicago: Henry Regnery Company.

Hanlon, J. M. (1968). Administration and education: Toward a theory of self-actualization. Belmont, CA: Wadsworth Publishing Company, Inc.

Heger, T., Pahl, A. T., Botta-Dukát, Z., Gherardi, F., Hoppe, C., Hoste, I., ... \& Kollmann, J. (2013). Conceptual frameworks and methods for advancing invasion ecology. Ambio, 42(5), 527-540. https://doi.org/10.1007/s13280-012-0379-x

Hosseini Dowlatabadi, F., Sadeghi, A., Saadat, S., \& Khodayari, H. (2014). Relationship Between Self-Efficacy and Self-Actualization with Coping Strategies Among Students. Research in Medical Education, 6(1), 10-17. https://doi.org/10.18869/acadpub.rme.6.1.10

Jones, A., \& Crandall, R. (1986). Validation of a short-index of self-actualization. Personality and Social Psychology Bulletin, 12, 63-73. https://doi.org/10.1177/0146167286121007

Joshanloo, M., \& Ghaedi, G. (2009). Psychometric Characteristics of Personal Growth Initiative Scale in University Students. Journal of Behavioral Sciences, 3(2), 121-125.

Lai, E. R. (2011). Metacognition: A literature review. Technical Report. Pearson Research Report.

Leclerc, G., Lefrançois, R., Dubé, R., \& Hébert R. (2003). Un instrument de mesure de l'actualisation de la personne à l'usage des praticiens. Interactions, 7(2), 21-46.

Limón, M. (2003). The role of domain-specific knowledge in intentional conceptual change. In G. M. Sinatra, \& P. R. Pintrich (Eds.), Intentional conceptual change. Mahwah: Lawrence Erlbaum Associates.

Marra, R. M., Kim, S. M., Plumb, C., Hacker, D. J., \& Bossaller, S. (2017). Beyond the Technical: Developing Lifelong Learning and Metacognition for the Engineering Workplace. In Proceedings of the Annual meeting of American Society for Engineering Education. https://doi.org/10.18260/1-2--27659

Maslow, A. (1943). A theory of human motivation. Psychological Review, 50(4), 370-396. https://doi.org/10.1037/h0054346

Maslow, A. (1968). Toward a psychology of being (2nd ed.). Princeton, NJ: Van Nostrand.

Mertler, C. A., \& Reinhart, R. V. (2017). Advanced and Multivariate Statistical Methods: Practical Application and Interpretation (6th ed.). Routledge Publishing.

Nielsen, W. S., Nashon, S., \& Anderson, D. (2009). Metacognitive engagement during field-trip experiences: A case study of students in an amusement park physics program. Journal of Research in Science Teaching, 46(3), 265-288. https://doi.org/10.1002/tea.20266

Papaleontiou-Louca, E. (2014). Metacognition. In Phillips, D. (Ed.), Encyclopedia of Educational Theory and 
philosophy (pp. 523-526). Thousand Oaks, CA: SAGE Publications.

Peña-Ayala, A., \& Cárdenas, L. (2015). A conceptual model of the metacognitive activity. In Metacognition: Fundaments, applications, and trends (pp. 39-72). Springer, Cham. https://doi.org/10.1007/978-3-319-11062-23

Robitschek, C., Ashton, M. W., Spering, C. C., Geiger, N., Byers, D., Schotts, G. C., \& Thoen, M. A. (2012). Development and psychometric evaluation of the Personal Growth Initiative Scale-II. Journal of Counseling Psychology, 59(2), 274-287. https://doi.org/10.1037/a0027310

Rogers, C. (1959). A theory of therapy, personality, and interpersonal relationships, as developed in the client-cantered framework. In S. Koch (Ed.), Psychology: A Study of a Science: Formulations of the Person and the Social Context (Vol. 3, pp. 185-256). New York: McGraw-Hill.

Rogers, C. R. (1951). Client-Cantered therapy. Boston: Houghton Mifflin Company.

Rogers, C. R. (1962). Toward becoming a fully functioning person. In A. W. Combs (Ed.), Perceiving, Behaving, and Becoming: A New Focus for Education. Washington DC: Association for Supervision and Curriculum Development. https://doi.org/10.1037/14325-003

Ross, M. R. (2004). Introduction to probability and statistics for engineers and scientists. San Diego: Elsevier Academic Press.

Schraw, G., Crippen, K. J., \& Hartley, K. (2006). Promoting self-regulation in science education: Metacognition as part of a broader perspective on learning. Research in Science Education, 36, 111-139. https://doi.org/10.1007/s11165-005-3917-8

Sinatra, G. M. (2005). The "warming trend" in conceptual change research: The legacy of Paul R. Pintrich. Educational psychologist, 40(2), 107-115. https://doi.org/10.1207/s15326985ep4002_5

Sperling, R. A., Howard, B. C., Staley, R., \& Du Bois, N. (2004). Metacognition and Self-Regulated Learning Constructs. Educational Research and Evaluation, 10(2). https://doi.org/10.1076/edre.10.2.117.27905

Taj, F., Taghipour, E., Sadeghi, M. S., \& Khoskonesh, A. (2013). The correlation of attachment styles with self-actualization in Psychotherapist in Tehran. Quarterly Journal of Career \& Organizational Counseling, 5(16), 28-45.

Wang, J. R., \& Chen, S. F. (2014). Exploring mediating effect of metacognitive awareness on comprehension of science texts through structural equation modelling analysis. Journal of Research in Science Teaching, 51(2), 175-191. https://doi.org/10.1002/tea.21131

Waterman, A. S. (2014). Self-Actualization. In A. C. Michalos (Eds.), Encyclopaedia of Quality of Life and Well-Being Research (pp. 5743-5746). Dordrecht: Springer Netherlands. https://doi.org/10.1007/978-94-007-0753-5_2626

Wiezbicki-Stevens, K. (2009). Metacognition: Developing Self-Knowledge Through Guided Reflection. University of Massachusetts, Dissertations.

Wilson, D., \& Conyers, M. (2016). Teaching Students to Drive Their Brains. ASCD.

Worrall, L., \& Bell, F. (2007). Metacognition and lifelong e-learning: A contextual and cyclical process. E-Learning and Digital Media, 4(2), 161-171. https://doi.org/10.2304/elea.2007.4.2.161

\section{Copyrights}

Copyright for this article is retained by the author(s), with first publication rights granted to the journal.

This is an open-access article distributed under the terms and conditions of the Creative Commons Attribution license (http://creativecommons.org/licenses/by/4.0/). 